\title{
ERRATUM
}

Surasak Sangkhathat $\cdot$ Takeshi Kusafuka

Akihiro Yoneda $\cdot$ Seika Kuroda $\cdot$ Yukichi Tanaka

Norio Sakai - Masahiro Fukuzawa

\section{Renal cell carcinoma in a pediatric patient with an inherited mitochondrial mutation}

Published online: 17 November 2005

(C) Springer-Verlag 2005

Pediatr Surg Int (2005). DOI 10.1007/s00383-005-

1471-0

Due to an unfortunate error, the wrong first name was given for the fifth author, Yukichi Tanaka.

The online version of the original article can be found at http:// dx.doi.org/10.1007/s00383-005-1471-0

S. Sangkhathat $\cdot$ T. Kusafuka $(\bowtie) \cdot$ A. Yoneda

S. Kuroda $\cdot$ M. Fukuzawa

Department of Pediatric Surgery, Osaka University

Graduate School of Medicine, 2-2 Yamadaoka,

Suita, Osaka 565-0871, Japan

E-mail: kusafuka@pedsurg.med.osaka-u.ac.jp

Tel.: + 81-6-68793754

Fax: + 81-6-68793759

Y. Tanaka

Division of Clinical Laboratory, Kanagawa Children's

Medical Center, Yokohama 232-8555, Japan

N. Sakai

Department of Pediatrics, Osaka University

Graduate School of Medicine, 2-2 Yamadaoka,

Suita, Osaka 565-0871, Japan 